\title{
Controle termo-higrométrico microambiental para animais de laboratório por meio de tecnologia termoelétrica: estudo experimental para roedores de laboratório
}

\author{
Termohigrometric microenvironmental control for laboratory animals through \\ thermoelectric technology: experimental study for laboratory animals
}

\author{
Alexandre MARTINEWSKI ${ }^{1}$; Nívea Lopes de SOUZA ${ }^{1}$; Élvio Franco de Camargo ARANHA²; José Luiz \\ Bernardino MERUSSE ${ }^{1}$
}

${ }^{1}$ Departamento de Patologia da Faculdade de Medicina Veterinária e Zootecnia da Universidade de São Paulo, São Paulo-SP
${ }^{2}$ Faculdade de Tecnologia de Sorocaba, Sorocaba-SP

\begin{abstract}
Resumo
Um condicionador de ar para biotérios foi montado com módulos termoelétricos de efeito Peltier. Para troca térmica foram empregados dissipadores externos a água, obtendo-se $\Delta \mathrm{t}$ de $21{ }^{\circ} \mathrm{C}$, rendimento de $46,02 \%$, consumo de 524 W/h. A simulação matemática de operação, com mistura de ar não condicionado, mostrou que o sistema pode servir a aproximadamente 137 microisoladores padrão rato com dissipação externa a água. O sistema termoelétrico mostrou ainda, precisão de $\pm 0,1^{\circ} \mathrm{C}$, nas temperaturas experimentais, o que é impossível num sistema de freon. Foram ensaiadas as seguintes temperaturas: $22^{\circ}, 24^{\circ}, 26^{\circ}, 28^{\circ}$ e $30^{\circ} \mathrm{C}$, obtendo sempre estabilidade e precisão, independentemente da temperatura ambiental onde o equipamento estava em operação.
\end{abstract}

Palavras-chave: Animais de laboratório. Módulos termoelétricos. Microambiente. Efeito Peltier.

\begin{abstract}
An air conditioner for animal facilities was mounted with thermoelectric modules of Peltier effect. For heat exchange, a water dissipation system was employed.The air temperature difference $(\Delta \mathrm{t})$ was $21^{\circ} \mathrm{C}$, the performance was $46.02 \%$ and the power consumption was $524 \mathrm{~W} / \mathrm{h}$. The mathematical simulation of operation, with mixture of no conditioned air showed that the system can serve approximately 137 standard mouse microisolators, with water dissipation system. The thermoelectric system also showed an accuracy of $\pm 0.1^{\circ} \mathrm{C}$ at the experimental temperatures, which is impossible in a system of Freon Gas. We tested the following temperatures: $22^{\circ}, 24^{\circ}, 26^{\circ}, 28^{\circ}$ and $30^{\circ} \mathrm{C}$, always getting stability and accuracy at any outside temperature.
\end{abstract}

Keywords: Laboratory animals. Thermoelectric modules. Microenvironment. Peltier effect.

\section{Introdução}

Assumindo uma visão conceitual, porém pragmática, Baumans et al. ${ }^{1}$ expôs seu conceito sobre o animal de laboratório em relação ao ambiente, considerando que os animais podiam ser afetados por 16 fatores físicos, químicos e microbiológicos presentes no ambiente, sendo nove deles ligados diretamente ao controle atmosférico.

Murakami e Zhang afirmam que, em salas onde se aplica a VGD, a ventilação no interior das caixas de animais pode ser deficiente, o que leva a um acúmulo de calor e de poluentes particulados e gasosos ${ }^{2,3}$.

Em países tropicais, de elevadas médias de temperaturas, a simples movimentação do ar facilita a retirada do calor sensível e latente dos animais, pela convecção forçada, o que propicia sensação de conforto tanto animal quanto humano ${ }^{4,5}$.

Segundo Macintyre ${ }^{4}$, a sensação de resfriamento do homem a uma velocidade do ar de $6,5 \mathrm{~m} / \mathrm{s}$ é de,

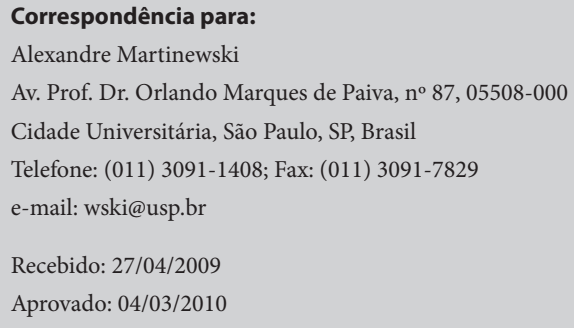

Agradecimentos: À Fundação de Amparo à Pesquisa do Estado de São Paulo, processo $\mathrm{n}^{\circ}$ 02/09908-0, pelo suporte financeiro. 
aproximadamente, $8^{\circ} \mathrm{C}$. Há, porém, limites para a indução de conforto pela simples ventilação. Umidades e temperaturas muito elevadas são fatores negativos para a criação animal. Os mecanismos de facilitação das trocas térmicas nos sistemas VMA, à temperatura ambiente, permitiriam, teoricamente, que fossem aumentadas as faixas de temperatura preconizadas para biotérios conforme literatura internacional ${ }^{6}$.

Os resultados obtidos até o momento e o sucesso na substituição de tecnologia convencional, por alternativa menos onerosa, permitem outra visão sobre as novas necessidades que moldam constantemente $o$ aperfeiçoamento tecnológico. Seguindo esta linha de raciocínio, o presente trabalho pretende analisar uma forma alternativa de tratamento termo-higrométrico (TTH) para o ar de insuflação de biotérios, a qual deverá operar em conjunto com o sistema VMA.

Atualmente os sistemas de TTH baseiam-se no ciclo de compressão do gás freon, o qual permite que parte da energia térmica do ar de insuflação seja removida, transferida e rejeitada para a atmosfera. Num ciclo básico de compressão de freon, o gás chega ao compressor que o remete para o condensador do sistema ou linha de alta pressão. No final do subciclo de condensação, praticamente toda a massa de freon já está liquefeita, tendo perdido o calor para o ambiente. A pressão na linha de condensação é mantida elevada graças à válvula de expansão ou tubo capilar, colocado no final desta linha. Este elemento causa uma drástica redução no diâmetro da linha de freon, provocando sua liquefação no trecho anterior. A partir da válvula de expansão, o diâmetro da linha é aumentado. Este aumento provoca a evaporação do freon e, portanto, este segundo subciclo recebe o nome de evaporador. A evaporação do freon provoca retirada de energia térmica da tubulação aletada do evaporador, pela qual, externamente, passa o ar de insuflação, que é, portanto, resfriado. A partir do evaporador, o vapor de freon aquecido retorna ao compressor, continuando o ciclo.
Os sistemas de compressão de freon são responsáveis por praticamente $90 \%$ de tudo o que é resfriado no planeta. Porém, este ciclo envolve considerável quantidade de peças móveis e, portanto, deve ser passível de manutenção preventiva periódica. Além disso, seu projeto e sua montagem envolvem um elevado grau de complexidade e o principal elemento do sistema, o freon, tem sido associado a danos ecológicos. Porém, sabe-se que este não foi o único ciclo de refrigeração desenvolvido nem a única forma de se obter refrigeração.

Baseados em Costa ${ }^{7}$, uma breve retrospectiva deve ser feita acerca de outra forma de obtenção do frio. Em 1821, Seebeck observou que em um circuito fechado constituído por dois metais diferentes, sempre que as duas junções forem mantidas a temperaturas diferentes, há geração de corrente elétrica. Dessa forma, verificou que diferenças de temperatura da ordem de $1.700{ }^{\circ} \mathrm{C}$ podiam gerar diferença de potencial de $18 \mathrm{mV}$. Em 1834, Peltier observou o efeito inverso: fazendo circular uma corrente elétrica na mesma direção da FEM (força eletromotriz), gerada pelo efeito Seebeck, ocorria o resfriamento dos metais no ponto de sua junção. Já, a circulação de corrente elétrica contrária à direção da FEM, aquecia o ponto da junção, caracterizando a reversibilidade do efeito. Os terminais metálicos nos quais se observava o efeito foram denominados de termopares. Estes fenômenos foram denominados de termoeletricidade e, respectivamente, Efeito Seebeck e Efeito Peltier. Até o ano de 1949 não existiam materiais que permitissem aplicações industriais para a termoeletricidade 8 . A partir desta data, iniciou-se o desenvolvimento de novos materiais, denominados semicondutores, que apresentavam Coeficientes Seebeck muito superiores aos dos metais e permitiram o início do desenvolvimento industrial de processos ligados à termoeletricidade. Em 1955 foi sintetizado o telureto de bismuto $\left(\mathrm{Bi}_{2} \mathrm{Te}_{3}\right)$, semicondutor que permitiu diferença de temperatura da ordem de $72{ }^{\circ} \mathrm{C}$ entre a face quente e a face fria. 
Outra vantagem do equipamento termoelétrico é a facilidade de sua montagem. Além disso, tais equipamentos não necessitam de manutenções tão frequentes pelo fato de praticamente não possuírem peças móveis, apenas pequenos ventiladores de longa vida útil e facilmente substituíveis.

Os avanços obtidos no campo do controle atmosférico de biotérios permitiram que fossem claramente definidos o microambiente (interior das caixas de animais) e o macroambiente (a sala onde são mantidas as caixas de animais).

A partir da década de 70, surgem relatos de sistemas os quais efetuavam a ventilação diretamente no interior das caixas de animais ${ }^{9,10,11}$.

Os procedimentos acima mencionados podem contribuir para a redução dos custos de um biotério, permitindo inclusive a adoção de equipamentos condicionadores de ar do tipo doméstico de janela para o macroambiente. Quanto ao microambiente, o processo de refrigeração foi realizado concomitantemente com um sistema VMA, o que permitiu o aproveitamento do fenômeno de convecção forçada de ar sobre os animais. Este fenômeno convectivo é mais eficiente que a convecção natural, e ocorre somente quando existe a indução de um vetor de velocidade de ar sobre um corpo aquecido ${ }^{12}$. Este fenômeno permitiu trabalhar, experimentalmente, com temperaturas de conforto para os animais acima daquelas citadas na literatura para biotérios, diminuindo, desta forma, as exigências frigorígenas do equipamento. $\mathrm{O}$ condicionador de ar para o microambiente deverá, desta forma, apenas remover a carga térmica gerada pelos animais.

\section{Material e Método}

\section{Montagem do sistema}

Foram utilizados módulos Peltier da empresa Advanced Thermoeletric. Dentre os modelos de módulos termoelétricos disponíveis, foi selecionado o modelo
ST-127-1.4-8.5, de 8,5 A; 17,5 V de tensão máxima de alimentação, 80 watts de potência nominal, $\Delta t_{\text {máx }}$ de $70{ }^{\circ} \mathrm{C}$ a $25^{\circ} \mathrm{C}$ de temperatura ambiente, medindo $40 \mathrm{x}$ $40 \times 3,95 \pm 0,22 \mathrm{~mm}$.

O módulo de condicionamento foi montado em formato de gincana com dissipação externa a água. Essas gincanas eram responsáveis pela troca de calor entre o módulo termoelétrico e o líquido de arrefecimento.

Para a manutenção da temperatura experimental, o sistema de condicionamento foi gerenciado eletronicamente via controlador eletrônico digital microprocessado $\left(\mathrm{COEL}^{\circ}\right)$, o qual modulava a corrente elétrica de alimentação por meio de contatores (Telemecanique $\left.^{\circledast}\right)$, o que permitiu variação máxima de $\pm 0.1^{\circ} \mathrm{C}$ da temperatura experimental.

\section{Desempenho do Sistema}

Por rendimento, entende-se a quantidade de trabalho executado por uma máquina ou sistema, em função da energia fornecida. A energia fornecida é a potência total $\left(\mathrm{P}_{\mathrm{T}}\right)$ e a quantidade de trabalho executado é a potencia útil $\left(\mathrm{P}_{\mathrm{U}}\right)$. Em sistemas teóricos denominados ideais, $\mathrm{P}_{T}=\mathrm{P}_{\mathrm{U}}$. Na prática, porém, sempre ocorrem perdas na execução de um trabalho e, portanto, $\mathrm{P}_{\mathrm{T}}>\mathrm{P}_{\mathrm{U}^{\prime}}$. A diferença entre essas duas potências é a chamada potência dissipada $\left(\mathrm{P}_{\mathrm{D}}\right)$, perdida sob forma de outras energias. Em virtude do princípio da conservação de energia tem-se então:

$$
\mathbf{P}_{\mathrm{T}}=\mathbf{P}_{\mathrm{U}}+\mathbf{P}_{\mathrm{D}}
$$

Como rendimento $\eta$, define-se a relação entre a $P_{U}$ e a $\mathrm{P}_{\mathrm{T}}$ :

$$
\eta=\mathbf{P}_{\mathrm{U}} / \mathbf{P}_{\mathrm{T}}
$$

$\mathrm{O}$ rendimento $\eta$ é um número adimensional ${ }^{13}$. Visto que o rendimento $\eta$ é um número puro, ou seja, não é associado a grandeza métrica alguma, pode-se, também, traduzir este rendimento $\eta$ em termos percentuais. Neste caso, $\eta$ pode ser quantificado percentualmente, numa relação entre grandezas da seguinte forma:

$$
\eta=\left(\mathbf{P}_{\mathrm{U}} \mathbf{x} 100\right) / \mathbf{P}_{\mathrm{T}}
$$




\section{Resultados}

\section{Desempenho do Condicionador Tipo Gincana com Dissipação Externa a Água}

A tabela 1 mostra a queda de temperatura ao longo do sistema de condicionamento com troca de calor a água logo após o início do ensaio até a estabilização do sistema.

O sistema proposto ficou caracterizado por apresentar dois picos distintos de elevação de temperatura, registrados nos termômetros 5 e 8, demonstrando que a massa de ar absorve calor nas curvas independente da forma de dissipação de calor externo utilizado.

A variação de entalpia referente a este teste pode ser visualizada no segmento da carta psicrométrica (Figura 1) para São Paulo - Brazil - Latidude 2330' Sul.

A energia fornecida ao sistema foi de 119,631 kJ. Esse valor foi obtido multiplicando-se o valor da po- tência instantânea fornecida $(0,5247 \mathrm{~kW} ; 1 \mathrm{~kW}=1 \mathrm{~kJ}$ por segundo) pelo tempo de realização do trabalho (228 segundos; 19 séries multiplicado pelo tempo de execução de cada série que foi de 12 segundos). Segundo a carta psicrométrica, a variação total de entalpia foi de 55,06 kJ.

A partir dos dados acima, obteve-se o seguinte rendimento $(\eta)$, aplicando-se os valores na equação (3):

$$
\begin{aligned}
& \eta=(55,06 \mathrm{~kJ} \times 100) / 119,631 \mathrm{~kJ} \eta \cong 0,4602 \\
& \text { ou } \eta \cong 46,02 \%
\end{aligned}
$$

Neste ensaio, em particular, notou-se TBS e TBU finais apresentando o mesmo valor $\left(1^{\circ} \mathrm{C}\right)$. Este fato é comum em sistemas de condicionamento de ar e representa uma condição psicrométrica denominada "ponto de orvalho", no qual todo vapor de água presente no ar condensa-se.

Tabela 1 - Temperaturas $\left({ }^{\circ} \mathrm{C}\right)$ dos 12 termômetros no sistema de condicionamento tipo gincana com dissipação externa a água, durante as 21 séries de medições. Condições elétricas de operação: tensão de alimentação de 9 volts por semicondutor, consumo total de 5,3 amperes e potência de 524,7 watts por hora. Velocidade do ar condicionado de $1 \mathrm{~m} / \mathrm{s}$ e vazão de 5,82 litros por

\begin{tabular}{|c|c|c|c|c|c|c|c|c|c|c|c|c|}
\hline & \multicolumn{12}{|c|}{ Termômetros } \\
\hline Séries ${ }^{\star}$ & 1 & 2 & 3 & 4 & 5 & 6 & 7 & 8 & 9 & 10 & 11 & 12 \\
\hline 1 & 23 & 23 & 23 & 23 & 23 & 23 & 23 & 23 & 23 & 23 & 23 & 23 \\
\hline 2 & 23 & 23 & 22 & 22 & 22 & 21 & 21 & 21 & 21 & 20 & 20 & 20 \\
\hline 3 & 23 & 22 & 21 & 20 & 20 & 20 & 20 & 20 & 19 & 19 & 19 & 19 \\
\hline 4 & 23 & 22 & 20 & 19 & 19 & 19 & 19 & 20 & 18 & 18 & 18 & 18 \\
\hline 5 & 23 & 21 & 19 & 19 & 19 & 18 & 17 & 18 & 17 & 16 & 16 & 16 \\
\hline 6 & 23 & 20 & 18 & 16 & 19 & 16 & 16 & 17 & 15 & 14 & 14 & 14 \\
\hline 7 & 23 & 20 & 17 & 15 & 18 & 15 & 15 & 17 & 14 & 12 & 12 & 12 \\
\hline 8 & 22 & 20 & 17 & 14 & 16 & 14 & 14 & 16 & 12 & 11 & 11 & 11 \\
\hline 9 & 22 & 20 & 16 & 13 & 15 & 13 & 13 & 15 & 11 & 10 & 10 & 10 \\
\hline 10 & 22 & 20 & 16 & 13 & 15 & 12 & 12 & 15 & 10 & 9 & 9 & 9 \\
\hline 11 & 22 & 19 & 15 & 12 & 15 & 11 & 11 & 13 & 9 & 8 & 8 & 8 \\
\hline 12 & 22 & 19 & 15 & 12 & 15 & 11 & 10 & 13 & 9 & 7 & 7 & 7 \\
\hline 13 & 22 & 19 & 15 & 12 & 15 & 10 & 10 & 13 & 8 & 6 & 6 & 6 \\
\hline 14 & 22 & 19 & 15 & 11 & 15 & 10 & 9 & 12 & 7 & 5 & 5 & 5 \\
\hline 15 & 22 & 19 & 15 & 11 & 15 & 10 & 9 & 12 & 7 & 5 & 5 & 5 \\
\hline 16 & 22 & 19 & 15 & 11 & 15 & 9 & 8 & 12 & 6 & 4 & 4 & 4 \\
\hline 17 & 22 & 19 & 15 & 11 & 15 & 9 & 8 & 12 & 5 & 3 & 3 & 3 \\
\hline 18 & 22 & 19 & 15 & 10 & 15 & 9 & 7 & 12 & 5 & 3 & 2 & 2 \\
\hline 19 & 22 & 19 & 15 & 10 & 15 & 8 & 7 & 11 & 3 & 2 & 1 & 1 \\
\hline
\end{tabular}
segundo. Vazão de água de arrefecimento de 1 litro por minuto - São Paulo - 2005

* Séries de tomadas de temperatura até a estabilização do sistema. Intervalos de tomadas de temperatura: 1 segundo entre cada termômetro e 12 segundos entre cada série 




Abaixo de $0^{\circ} \mathrm{C}$ as Propriedades e Linhas de Correção de Entalpia, sẵo para Gelo

Figura 1 - Variação de entalpia utilizando condicionador tipo gincana com dissipação externa a água. (A) Temperatura de bulbo seco inicial; (B) Temperatura de bulbo úmido inicial; (C) Temperatura de bulbo seco final; (D) Temperatura de bulbo úmido final; (E) Entalpia inicial e (F) Entalpia final

\section{Simulação Matemática de Operação dos Sistemas}

Em uma situação hipotética, baseada nos dados obtidos até o momento, objetivando a comparação direta entre os ensaios, foi calculada a quantidade de microisoladores que podem ser beneficiados com o uso do sistema proposto. Esta é uma simulação matemática que pode ser perfeitamente aplicada a situações reais, respeitando as condições ambientais para cada caso.

Usando o recurso de diluição de fluidos, recurso este amplamente utilizado em sistemas convencionais para condicionamento de ar, pode-se chegar a uma temperatura final misturando duas massas de ar a temperaturas distintas. Para isso deve-se usar a seguinte fórmula:

$$
\frac{(\operatorname{VolC} \times T e m p C)+(\operatorname{VolE} \times T e m p E)}{V o l C+\text { VolE }}=T e m p F
$$

Aplicando-se valores hipotéticos na equação (4), tem-se:

$$
\frac{(20952 \times 9)+(\text { VolE } \times 30)}{20952+\text { VolE }}=22
$$

Onde: VolC

$=20952$ litros; $V o l E=$ Volume de ar externo, não condicionado; TempC $=9{ }^{\circ} \mathrm{C} ; \operatorname{Tem} p E=30^{\circ} \mathrm{C} ; \operatorname{Tem} p F=22^{\circ} \mathrm{C}$. Obtém-se então VolE = 34047 litros de ar. 
Ou seja, a uma temperatura ambiente (ar externo) de $30^{\circ} \mathrm{C}$, a gincana de condicionamento, seria capaz de fornecer uma massa de ar total de 54999 litros $($ VolC + VolE $)$ a uma temperatura de $22^{\circ} \mathrm{C}$. Essa massa de ar deve ser dividida pelo volume do microisolador (20 litros, microisolador para ratos, volume aproximado) e posteriormente dividida pelo número de trocas de ar que se deseja no microisolador (neste caso assumiu-se 20 renovações completas de ar por hora). Dessa forma, este sistema é capaz de suprir aproximadamente 137 microisoladores, consumindo 524,7 watts por hora.

\section{Discussão}

Os módulos termoelétricos transferem energia térmica de uma de suas superfícies para outra. Dessa forma, os ensaios foram feitos objetivando otimizar a dissipação desta energia de uma das faces dos módulos. Embora já fosse conhecido que a transferência de calor por condução guarda uma relação direta de eficiência com a densidade do meio, optou-se pela realização de um ensaio visando à rejeição do calor para a água por meio de dissipadores especialmente projetados para este fim. De posse destes resultados, considerou-se válida a verificação do rendimento a partir do arrefecimento dos módulos (Tabela 1). Neste ensaio, obteve-se $\Delta \mathrm{t}$ de $21^{\circ} \mathrm{C}$, variação de entalpia $55,06 \mathrm{~kJ}$ e $\eta \cong 46,02 \%$, manteve-se a vazão de ar e 1 $1 / \mathrm{m}$ de vazão de água de arrefecimento e consumo elétrico foi de $\cong 524 \mathrm{~W} / \mathrm{h}$.

Com referência a eventuais módulos comerciais, os resultados apontam para a necessidade de trocas térmicas a água, com recirculação. Dessa forma, para uma operação em regime de refrigeração do ar, o calor absorvido pela água de arrefecimento seria rejeitado em um dispositivo semelhante a um radiador, com circulação por bomba d'água. No ciclo inverso (aquecimento do ar), o calor seria absorvido da água e rejeitado para a massa de ar a ser aquecida. $\mathrm{O}$ uso comercial da TT exige também que os módulos se- jam suficientemente compactos, o que poderia ser conseguido com a montagem de sequências paralelas de módulos de condicionamento, dispostas em um ou mais planos distintos, na dependência das vazões envolvidas. Desta forma, não existe limite máximo para o número de módulos de condicionamento a serem utilizados em conjunto.

Uma prática comum em tecnologia de condicionamento de ar constitui-se na simulação matemática de operação de sistemas. Da mesma forma, a maioria dos sistemas convencionais de condicionamento opera com mistura de ar, ou seja, mistura-se a massa de ar condicionado, de recirculação, com determinada massa de ar externo, não condicionado e o resultado da mistura é insuflado no ambiente. Este procedimento é válido para instalações de conforto humano, não podendo ser adotado em biotérios em virtude do aumento exponencial dos níveis de vapor de amônia. Por outro lado, para biotérios, pode-se adotar o procedimento de mistura de ar condicionado ao ar não condicionado, desde que se efetue o expurgo completo da mistura. As simulações matemáticas efetuadas basearam-se neste procedimento e revelaram a capacidade para condicionamento de aproximadamente 137 gaiolas fechadas tipo microisoladores, com volume aproximado de 20 litros, usualmente utilizadas para manutenção de ratos.

Neste ponto, é importante citar, novamente, a característica de facilitador do mecanismo de convecção forçada dos sistemas microambientais. Para as simulações efetuadas, foram assumidos valores de $30^{\circ} \mathrm{C}$ para TempE e $22^{\circ} \mathrm{C}$ para TempF. Na dependência da velocidade do ar aplicada ao sistema, o nível de $22{ }^{\circ} \mathrm{C}$ para TempF poderia ser extremamente desconfortável para os animais. Isso significa que em tais sistemas pode-se trabalhar com faixas de temperatura mais elevadas, portanto menores diferenças entre TempE e TempF, o que, na prática significa que, para uma vazão e temperatura de ar condicionado constantes, podese aumentar a porcentagem de ar não condicionado 
da mistura ou utilizar um número menor de unidades termoelétricas. Importante ressaltar que, independente da solução adotada, o resultado tenderá sempre à diminuição dos custos.

Outras duas características do sistema operando com tecnologia termoelétrica devem ser ressaltadas. Uma delas é a precisão da faixa de temperatura mantida. O sistema montado operou com variação de $\pm 0,1{ }^{\circ} \mathrm{C}$, o que é impossível de ser obtido em sistemas convencionais de compressão de freon. Isso possibilita um extremo refinamento em experimentos nos quais a exatidão da temperatura seja fator primordial, como por exemplo, em câmaras climáticas. A segunda é a reversibilidade do fenômeno termoelétrico, o que na prática significa que a massa de ar pode ser resfriada ou aquecida pelo mesmo sistema, apenas com inversão do sentido da corrente elétrica de alimentação dos módulos Peltier. Este fato também é impossível num sistema de compressão de freon de grande porte. Nos sistemas de pequeno porte, até 60.000 BTU's, isso é feito com a inversão do fluxo de freon, quando o evaporador passa a funcionar como condensador e vice-versa. Os ciclos de grande porte envolvem compressores de grande potência, maior atrito e maior geração de calor, o que exigiria condensadores muito grandes, em relação às unidades evaporadoras o que torna elétrica e termodinamicamente inviável a inversão do ciclo. Sistemas de compressão de freon de grande porte possuem uma resistência elétrica exclusiva para o aquecimento da massa de ar para os animais, em situações de baixa temperatura externa.
Deve-se ressaltar que, sob condições de ventilação microambiental, existe uma forte influência do fator "convecção forçada" sobre os animais. Tal fenômeno permite que se obtenha, nestes, sensação térmica de conforto com temperaturas de ar maiores do que as citadas pela literatura mundial para sistemas convencionais. Mesmo sem qualquer rebaixamento da temperatura de bulbo seco de determinada massa de ar, somente o deslocamento dessa massa sobre um organismo (convecção forçada), já é capaz de remover energia térmica, provocando uma sensação de resfriamento que poderá chegar até o desconforto na dependência da velocidade dessa massa de ar, da umidade presente e, obviamente, da temperatura dessa massa de ar.

A ciência de animais de laboratório tem um viés extremamente prático no sentido de se aproximar muito a uma linha de produção industrial. Nesse sentido, buscou-se o desenvolvimento de um equipamento com potencial para ser competitivo no mercado.

OBSERVAÇÕES: O presente trabalho foi desenvolvido como parte da Tese de Doutorado do primeiro autor, junto ao Programa de Pós-Graduação em Patologia Experimental e Comparada do Departamento de Patologia da Faculdade de Medicina Veterinária e Zootecnia da Universidade de São Paulo. Recebeu suporte financeiro da Fundação de Amparo à Pesquisa do Estado de São Paulo, processo no 02/09908-0 e encontra-se em fase de patenteamento junto ao Instituto Nacional da Propriedade Industrial (INPI) sob o No PI 8.800.860-4. 


\section{Referências}

1. BAUMANS, V.; SCHLINGMANN, F.; VONCK, M.; VAN LITH, H. A. Individually ventilated cages: beneficial for mice and men? Contemporary Topics In Laboratory Animals Science, v. 40, n. 5, p. 25-30, 2001.

2. MURAKAMI, H. Differences between internal and external environments of the mouse cage. Laboratory Animal Science, v. 21, n. 5, p. 680-684, 1971.

3. ZHANG, Y. A survey of laboratory rat environment. ASHRAE Transactions: symposia, v. 98, n. 2, p. 247-343, 1992.

4. MACINTYRE, A. J. Ventilação industrial e controle da poluição. Rio de Janeiro: Guanabara Koogan, 1990. p. 1-3, 26-36, 92-104.

5. MESQUITA, A. L. S.; GUIMARÃES, F. A.; NEFUSSI, N. Engenharia de ventilação industrial. São Paulo: CETESB, 1988. p. 121-188.

6. SOCIETY FOR LABORATORY ANIMAL SCIENCE. Committe on Training and Correct Housing of Laboratory Animals. On the planning and structure of animal facilities for institues performing animal experiments. 2. ed. Basel: Solas, 1989. p. 39-48.
7. COSTA, Ê. C. Refrigeração. São Paulo: Edgard Blucher, 1982. p. 215-221.

8. ROWE, D. M. CRC handbook of thermoelectrics. Washington, D.C.: CRC, 1994. p. 7-41, 211-238.

9. GAMBLE, M. R.; CLOUGH, G. Ammonia build-up in animal boxes and its effect on rat tracheal epithelium. Laboratory Animals, v. 10, n. 2, p. 93-104, 1976.

10.GORTON, R. L. System design and energy conservation considerations. ASHRAE Transactions: symposia, v. 81, pt. 2, p. $572-578,1975$.

11.GORTON, R. L.; WOODS, J. E.; BESCH, E. L. System load characteristics and estimation of annual heat loads for laboratory animal facilities. ASHRAE Transactions: symposia, v. 82, pt 1, p. 107-112, 1976.

12.HOLMAN J. P. Heat transfer. São Paulo: MacGraw-Hill Inc., 1981.

13. PELEGRINI, M. Manual compacto de física: teoria e prática. São Paulo: Rideel, 1997. p. 141-167. 